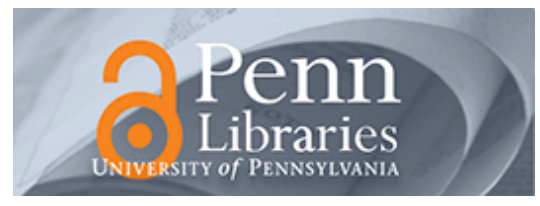

University of Pennsylvania

ScholarlyCommons

Management Papers

Wharton Faculty Research

2014

\title{
A Supply-Chain Approach to Talent Management
}

J. R. Keller

Peter Cappelli

University of Pennsylvania

Follow this and additional works at: https://repository.upenn.edu/mgmt_papers

Part of the Business Administration, Management, and Operations Commons, Business Intelligence Commons, Human Resources Management Commons, Management Information Systems Commons, Management Sciences and Quantitative Methods Commons, Organizational Behavior and Theory Commons, and the Strategic Management Policy Commons

\section{Recommended Citation (OVERRIDE)}

Keller, J.R. \& Cappelli, P. (2014). A Supply-Chain Approach to Talent Management. In Sparrow, P., Scullion, H., \& Tarique, I. (Eds.), Strategic Talent Management: Contemporary Issues in International Context, 117-150. Cambridge University Press.

This paper is posted at ScholarlyCommons. https://repository.upenn.edu/mgmt_papers/306

For more information, please contact repository@pobox.upenn.edu. 


\title{
A Supply-Chain Approach to Talent Management
}

\author{
Abstract \\ Talent management is the process through which employers anticipate and meet their needs for human \\ capital. It is about getting the right people with the right skills into the right jobs at the right time. It is a lot \\ to get right, and few organizations do. The difficulty in getting it right is a problem for firms insofar as \\ talent-management decisions shape firm competencies and success. It is a problem for workers, \\ because these decisions impact their careers. And it is ultimately a problem for society, because these \\ decisions, in aggregate, ultimately affect economic growth and social stability. \\ Disciplines \\ Business Administration, Management, and Operations | Business Intelligence | Human Resources \\ Management | Management Information Systems | Management Sciences and Quantitative Methods | \\ Organizational Behavior and Theory | Strategic Management Policy
}


(2011). Human capital, capabilities and the furm: literati, numerati, and entrepreneurs in the 21st-century enterprise. In Alan Burton-Jones and J.-C. Spender (eds.) The Oxford Handbook of Human Capital. Oxford: Oxford University Press, pp. 527-62.

Teece, D. J., Pisano, G., and Shuen, A. (1997). Dynamic capabilities and strategic management. Strategic Management Journal, 18 (7), 509-33.

Tjosvold, D. (1985). Implications of controversy research for management. Journal of Management, 11 (3), 21-37.

Wernerfelt, B. (1984). A resource-based view of the firm. Strategic Management Journal, 5 (2), 171-80.

Wheelwright, S. C. and Clark, K. B. (1992). Revolutionizing Product Development: Quantum Leaps in Speed, Efficiency, and Quality. New York, NY: Free Press.

Winter, S. G. (2003). Understanding dynamic capabilities. Strategic Management Journal, 24 (10), 991-5.

\section{A supply-chain approach to talent} management

J.R. KELLER AND PETER CAPPELLI

\subsection{Introduction}

Talent management is the process through which employers anticipate and meet their needs for human capital. It is about getting the right people with the right skills into the right jobs at the right time. It is a lot to get right, and few organizations do. The difficulty in getting it right is a problem for firms insofar as talent-management decisions shape firm competencies and success. It is a problem for workers, because these decisions impact their careers. And it is ultimately a problem for society, because these decisions, in aggregate, ultimately affect economic growth and social stability.

If there is an upside to this problem, it is that we can easily identify its cause. The central new aspects of business are uncertainty and change, yet traditional workforce-planning models were based on predictability and stability, which allowed organizations to forecast demand with a relatively high degree of accuracy. The supply of talent was assumed to be under the organization's control, given the prevalence of internal labor markets and single-firm careers. As the external environment became more difficult to forecast and traditional internal labor markets began to disintegrate, the inability of these strategic workforce planning systems to account for uncertainty in demand and disruptions in supply led many organizations to abandon them altogether.

Talent management has, as a result, become little more than a guessing game for most organizations. Only $19 \%$ of companies responding to a Conference Board survey reported engaging in any sort of structured workforce planning in the mid 1990s. Moreover, of the respondents to a survey specifically targeting companies interested in talent management, more than half reported to relying on "ad-hoc" approaches. Put differently, over half of these organizations reported relying on "ad-hoc planning," which really means they engaged in no planning at all. Yet organizations consistently report that managing the 
supply and demand for talent, especially for skilled workers, remains a top concern (SHRM, 2002, 2004, 2006, 2008, 2011), with a 2010 global survey identifying managing talent, improving leadership development, and strategic workforce planning as the top three priorities for human resources professionals (Strack et al., 2010).

What we need, then, is an approach to talent management that embraces planning in an environment characterized by uncertainty in supply and demand, one that acknowledges the inability to forecast away uncertainty and plan years into the future. Thankfully, the increasingly sophisticated literature on supply-chain management offers just such an approach. Supply-chain management is about delivering the right amount of product at the right price to meet demand at any given time - quite similar to the goal of the talentmanagement process. What supply-chain researchers have come to recognize - and account for theoretically and empirically - is that in reality, uncertainty in demand and disruptions in the supply chain make it all but impossible to achieve this goal with any regularity (Fisher and Rayman, 1996; Mabert and Venkataramanan, 1998). As a result, the supply-chain literature has taken a keen interest in understanding how organizations make sourcing decision under conditions of uncertainty (Fisher, 1997).

Adopting a supply-chain approach to talent management allows us to explore two pressing questions. First, how do organizations ensure a sufficient supply of human capital when both demand and supply are uncertain? Answering this question from a supply-chain perspective requires us to recognize that forecasting under conditions of uncertainty is incredibly difficult, almost inevitably leading to either an undersupply or oversupply of human capital. As a result, the focus shifts from meeting a point estimate of demand to minimizing the costs incurred as a result of these inevitable errors.

Second, what are the different human capital sourcing strategies available to firms, and when should each be used? Here, a supplychain perspective is helpful because researchers are particularly interested in how firms combine internal and external sourcing in order to minimize the costs associated with undershooting or overshooting actual demand. The reliability and responsiveness of the available sourcing options, as well as whether those options are designed to mitigate potential disruptions to the supply chain or are more contingent in nature, emerge as key considerations.

\subsection{A supply-chain perspective}

We should be clear on what it means to adopt a supply-chain perspective. Operations researchers have offered various definitions of a supply chain, but generally agree that a supply chain consists of all parties involved, directly or indirectly, in transforming raw material into finished products and delivering them to customers (Mabert and Venkataramanan, 1998). The length and complexity of an organization's supply chain is a function of the goods it produces and the customers that it serves. Research on all varieties of supply-chain configurations has consistently shown that supply-chain efficiency, reliability, and responsiveness are key drivers of a firm's profitability (Hendricks and Singhal, 2005). Supply-chain management, in turn, is concerned with how to ensure the efficiency, reliability, and responsiveness of supply chains.

The ideal supply chain would deliver just the right amount of product at the right price to meet demand at any given time, equivalent to a justin-time production strategy (Frazier, Spekman, and Oneal, 1988). Given that it takes time for raw materials to move through even the shortest supply chain, uncertainty in demand and disruptions in the supply chain are always potential problems. Recognizing this, operations researchers have developed theory and models enabling us to understand how to minimize the risks associated with making sourcing decisions under conditions of uncertainty (Fisher, 1997).

The sources of uncertainty in supply chains are less important to understand at this point than their effects. Uncertainty makes it difficult to forecast demand. Organizations should, and still do, generate point estimates of demand, but these forecasts inevitability contain some degree of error (Cappelli, 2009a). Even the most sophisticated forecasting models, which attempt to model or deal with uncertainty in some way, generate estimates with substantial variance (Fisher and Rayman, 1996). Further, disruptions in the supply chain make it difficult to meet demand forecasts, even if they are accurate (Tomlin, 2006). As a result, supply-chain theorists have de-emphasized the goal of meeting a point estimate of demand, characteristic of much of the literature on formal planning systems in organizations (e.g., Wood and LaForge, 1979; Kulda, 1980), instead advocating for the more realistic goal of minimizing the costs associated with undershooting or overshooting demand. 
The choices an organization makes regarding how it sources its inputs is a key determinant of its ability to minimize these costs. Sourcing involves both the procurement of material on the market as well as internal product development (Mabert and Venkataramanan, 1998). Minimizing mismatch costs, therefore, involves strategic decisions regarding how to combine internal and external sourcing, or deciding which products and how much of those products should be made internally and what and how much should be outsourced.

This is precisely why we view a supply-chain perspective as a natural fit for advancing our understanding talent-management decisions. At its most basic level, talent management is a matter of anticipating the need for human capital and setting out a plan to meet it. Yet these decisions are made under conditions of increasing uncertainty, where the supply and demand for human capital are difficult to forecast with any degree of accuracy. Internal sourcing, transforming raw material into a finished product, is the equivalent of internal talent development, while external sourcing is the equivalent of external hiring (Cappelli, 2008). A supply-chain perspective directs our attention to understanding how firms combine internal and external sourcing development and hiring - to meet estimated demand in a way that minimizes the mismatch costs associated with an oversupply or undersupply of human capital within the firm (Cappelli, 2008; Collings and Mellahi, 2009).

\subsection{A brief history of approaches to talent management}

It may surprise some readers that most firms are only just beginning to confront the challenge of combining internal and external sourcing to meeting their human capital needs. Rather, companies have generally adopted one of two approaches to talent management, depending on the prevailing external environment. The most common approach used today - and in several other periods throughout history - is reactive, with companies relying almost exclusively on external hiring to meet human capital needs as they arise. A second approach, rarely used today except in a few large firms, relies almost exclusively on internal development. Neither approach is likely to be particularly effective in today's competitive environment, where uncertainty in the demand for human capital is high and disruptions in the supply of human capital are frequent.
Talent management did not become a serious concern until companies grew complicated enough to have real management jobs to fill. Prior to the growth of the major railroads in the late nineteenth century, the typical firm had a simple structure where the owners were the managers (Chandler, 1977). And even then there was often little to manage, as organizations typically outsourced much of the work, from sales and distribution at companies such as DuPont (Zunz, 1990) to actual production tasks, which were often outsourced to contractors who found their own workers and managed them how they saw fit (Clawson, 1980: pp. 72-80).

Starting with the railroads, organizations began to expand to the point where the need for standardization and coordination became paramount, leading to the creation of what we would now call middle management jobs. These new positions were filled primarily through external hiring. Indeed, when the World War I Manpower Commission was established by the government to ensure that companies had the workers and skills needed to maintain wartime production, one of its specific goals was to reduce the ubiquitous pirating of workers by competitors. This also led to the rapid establishment of personnel departments to execute workforce planning practices throughout the 1920s (Jacoby, 1997). Yet these efforts were short lived, as the Great Depression eroded the need for managers (Melman, 1951) and with it the need for talent management. Talent development efforts remained stagnant throughout World War II, despite increases in demand, as most of the candidates who would have been hired into entry-level positions were serving in the military.

The lack of hiring and development from the Depression through World War II led to a serious shortage of talent across nearly all industries (Whitmore, 1952). Organizations responded just as they had at the beginning of the century - by raiding competitors for talent. A prominent retail executive noted that "to go to another store for assistant buyers, buyers, and other executives" was the approach "almost universally used" to meet their human capital needs (Carden, 1956 cited in Cappelli, 2009b). Yet external hiring proved insufficient in meeting the demand for talent, as pension plans with onerous vesting requirements, high marginal tax rates, and a lack of housing decreased the attractiveness of switching employers, even when competitors were able to offer higher salaries (Cappelli, 2010). 
The difficulty in finding external talent led companies to the realization that they needed to develop talent internally. With precious little experience of doing so themselves, they turned to the military for help. Recognizing the need for a huge expansion of its officer ranks in a short period of time leading up to World War II, the Navy began what was arguably the first truly systematic effort at large-scale succession planning, resulting in the publication of "Personnel Administration at the Executive Level" in 1948, which the Industrial Relations faculty at Princeton (Princeton University, 1949) summarized as:

A principally graphic report of the composite practices of 53 companies in regard to executive inventory control. In these companies, reserves of trained executives are built up through five basic steps: (1) organization analysis, (2) selection, (3) evaluation, (4) development, and (5) inventory control.

Clearly borrowing language from the field of operations, this document was widely used by many companies as the basis for building their own talent-development programs (Business Week, 1949). These programs, in turn, served as the basis for the "organizational man" model of the $1950 \mathrm{~s}$ in which expectations of lifetime employment and steady advancement opportunities emerged (Whyte, 1956). Companies began to rely almost exclusively on internal development. In 1943, the Conference Board could not find enough employers offering talentdevelopment programs to study them, yet by 1955 they were present in $60 \%$ of companies with 10,000 or more employees. Newcomer's (1955) study of corporate executives found that $80 \%$ had been developed from within by 1950 , compared to $50 \%$ in 1900 .

Yet these efforts were also short lived, as changes in the way business operated in the early 1980 s rendered the organizational-man approach to talent development obsolete. Firms in the United States experienced a sharp decline in the need for managerial talent following the 1981 recession and subsequent "re-engineerings" that led to flatter organizations, resulting in wholesale managerial layoffs (Cappelli, 1999: Chapter 4). Competition increased due to product market deregulation and internal competition (Useem, 1993) and consumer demands began to change more rapidly (Ghemawat, 1986), leading firms to move away from traditional employment systems (Stalk, 1988). This made it increasingly difficult for firms to forecast consumer demand and, as a result, to forecast their own human-capital needs. This, in turn, made firms reluctant to invest in the development of employees they may not need. The influence of financial markets also grew considerably during this time, encouraging firms to maintain more tentative employment ties (Davis, 2009: p. 28).

The peak of strategic workforce planning was probably a late-1960s model called MANPLAN, which attempted to model the movement of individuals within a career system by including individual behavior and psychological variables, supervisory practices, group norms, and labor market outcomes (Cappelli, 2008: p. 1). By 1984, only 9\% of employers reported using elaborate statistical regression models to forecast talent needs and only $6 \%$ used sophisticated Markov-chain vacancy models (Cappelli, 2008). Even where they were used, formal planning systems seemed to have little effect on firm performance (Nkomo, 1987).

Not surprisingly, these changes led organizations to rely, yet again, on external hiring to meet their human-capital needs. This strategy worked well until the mid $1990 \mathrm{~s}$, when the excess talent available as a result of the earlier waves of restructurings began to dry up. Talent has become harder to find and more expensive as employers bid up salaries poaching from one and other. An ever-increasing amount of evidence suggests that external hires rarely work out as well as expected (Groysberg, Lee, and Nanda, 2008; Dokko, Wilk, and Rothbard, 2009; Bidwell, 2011).

If nothing else, this history reveals that - as the saying goes - history is bound to repeat itself. Over the past century, organizations have alternatively met their need for talent primarily through external hiring (late 1800s up to World War I), internal development (World War I until the Great Depression), external hiring again (post-World War II), internal development again (organizational-man model of the 1950 s and 1960s), and back to external hiring today. Neither approach provides a sufficient means for meeting an organization's talent needs in an uncertain and rapidly changing environment. Recouping big investments in talent development can be difficult if human-capital needs change and if employees leave, both common occurrences. Relying solely on external hiring, on the other hand, leaves employers at the mercy of the labor market, resulting in talent shortfalls and other costs whenever labor markets tighten.

A key point of advancement in the field of supply-chain management came when scholars first recognized and began to account for the uncertainty that exists in managing the flow of products through the 
supply chain (Cohen and Lee, 1988; Mabert and Venkataramanan, 1998), resulting in the insight that strategically combining internal and external sourcing can help minimize the potential costs associated with operating under considerable uncertainty. In much the same way, recognizing uncertainty in both the demand for and supply of talent requires us to abandon talent-management approaches reliant on either external hiring or internal development and to instead consider how organizations can effectively combine hiring and development in order to meet their human-capital needs.

\subsection{Minimizing mismatch costs in the human-capital supply chain}

From a supply-chain perspective, the ideal talent-management system would provide just the right supply of human capital (i.e., employees) at a given point in the organization (i.e., in a job) at any given time, ostensibly a just-in-time human capital strategy. As with the production of goods and services, however, uncertainty in the demand and supply of human capital makes it all but impossible to achieve this goal with any regularity. Where does this uncertainty come from?

\subsubsection{Sources of uncertainty}

One source of supply-side uncertainty arises from the difficulty in predicting skills and competences needed in the future. If the skills and competences needed in the future change dramatically, a supply chain that looks robust now may look deficient in the future. A second source of supply-side uncertainty comes from the difficulty in predicting employee turnover. While organizations can use historic turnover rates to predict future exit rates, voluntary turnover is often driven by individual and environmental factors beyond the organization's control (Bretz, Boudreau, and Judge, 1994; Judge and Watanabe, 1995), introducing substantial error into these predictions. Additionally, firms have limited control over the future availability of skills and competences available on the labor market. Firms do exert indirect control over the future supply of such skills and competences, as when current demand influences the choice of college majors (Fiorito and Dauffenbach, 1982). Interestingly, however, a key concept in the supply-chain literature, the bullwhip effect, suggests that this is unlikely to be particularly effective in meeting future demand. The basic idea of the bullwhip effect is that small changes in demand toward the delivery end of the supply chain induce much larger fluctuations further down the supply chain (Lee, Padmanabhan, and Whang, 1997). Applied to the labor market more broadly, what often occurs is that when demand for a certain set of skills is high, students flock to majors in which they learn those skills. Given the time lag in acquiring those skills, however, by the time they reach the market there is often an oversupply of qualified candidates, which then decreases students enrolling on those majors, resulting in a subsequent shortage in the future, a cycle that can persist ad infinitum. Adding more difficulty is the fact that employers often signal to universities the skills they think they are going to need, but those needs are subject to changes on the demand side over which the organization often has little control.

Uncertainty on the demand side arises from changes in a firm's competitive environment. Industry deregulation, the rise of low-cost non-union competitors, increased global competition and the increasing influence of institutional investors and financial markets in general have all led to increased competition (Cappelli, 1995; Davis, 2009). Consumer demands have forced companies to shorten the development time on new products, quickly introduce updated models, increase product selection, and engage in mass customization (Fisher, 1997). Taken together, these changes have made it incredibly difficult to forecast demand for a firm's products and services, which in turn has made it difficult to forecast the human capital needed to produce and deliver those products and services. Linking back to the supply side, the rapidly changing technological landscape has further complicated firms' abilities to anticipate which skills and abilities they will need, and in which amounts, in order to meet future demand.

This combined uncertainty regarding the supply and demand of human capital has effectively eliminated most organizations' ability to accurately forecast their future human-capital needs and plan for the future. Historically, formal planning systems in general (Wood and LaForge, 1979; Kulda, 1980) and workforce planning systems in particular (Walker, 1980; DeVanna, Forbrum, and Tichy, 1981) have emphasized generating an exact forecast, or a point estimate of demand. Given what we know from the supply-chain literature - that meeting a point estimate of demand is essentially impossible - it is not entirely surprising that in reviewing a number of research studies, 
Nkomo (1987) concluded that empirical results have failed to show a consistent link between strategic planning (including human-resource planning) and organizational performance. A more appealing theoretical approach is one that shifts the emphasis from meeting a target forecast to minimizing and dealing with the inevitable glitches that result in the inevitable undersupply or oversupply of human capital.

A supply-chain approach to talent management is appealing, then, precisely because it begins with the assumption that under conditions of uncertainty forecasts will be wrong and a firm's ability to exactly meet its need for talent at any given time is highly unlikely. We therefore need to consider the ways in which an organization can be wrong and the costs of being wrong.

\subsubsection{Mismatch costs}

There are two ways to be wrong. The first is having a surplus of talent on hand at a given time. The second is a talent shortage. In the language of supply-chain management, these problems of oversupply and undersupply collectively result in what are known as mismatch costs (Lee, 2002; Chopra and Sodhi, 2004). Mismatch costs are the costs of being wrong: the costs incurred when there is a mismatch between demand and supply. As Hendricks and Singhal (2005: 696) note, a long line of literature has discussed the negative economic consequences of mismatches, including their effect on revenues, costs, and asset utilizations, all of which "are likely to adversely affect the short and long-term profitability of the firm." Minimizing these mismatch costs thus becomes the central talent-management concern.

If the costs of oversupply and undersupply were always equal, the best strategy would, in fact, be to try to meet the point estimate of demand, similar to the prescriptions offered by earlier formal planning models. A key insight from the supply-chain field, however, is that the mismatch costs associated with oversupply and those associated with undersupply are rarely equal (Olivares, Terwiesch, and Cassorla, 2008); what really matters are the relative costs of oversupply and undersupply. Translated into the talent-management context, it is easy to imagine that the cost of having ten too many salespeople on the retail floor is likely to be quite different than the cost of having ten too few salespeople. It is therefore critical to assess the relative costs of each type of error; how does the cost of having an excess worker compare to the cost of a shortage of one worker? More generally, is it more or less costly to have too few as compared to too many workers?

The implications of this line of thinking are remarkably straightforward. Where the mismatch costs associated with an oversupply are higher, erring on the side of having fewer workers will minimize mismatch costs. In the talent-management context, oversupply costs include the investments in training that walk out of the door when employees leave due to a lack of advancement opportunities, the severance costs associated with terminating underutilized employees, and the pressure to restructure or "reduce fat" in order to lower shortterm costs, among others. Where the mismatch costs associated with an undersupply are higher, erring on the side of having excess workers will minimize mismatch costs. Undersupply costs include the costs of outside hiring, lost productivity, or lost business opportunities due to worker shortages. And where the costs are roughly equal, then the best strategy is to try to meet the point estimate of demand.

The relative costs of each type of error are likely to vary not just across organizations, but also by job. For example, jobs vary in the extent to which they require firm-specific skills, as well as both the price and availability of external candidates in the labor market. In jobs that primarily require general skills, where those skills are readily available on the external market, and where the market rate is close to the internal wage, the costs of having too few workers are likely to be relatively low. In contrast, in jobs that require firm-specific skills, where those skills are more difficult to find externally and where search and compensation costs come at a premium, the costs of undersupply are likely to be quite high.

\subsection{Sourcing strategies for minimizing mismatch costs}

We now have an answer to the first question raised by adopting a supply-chain approach - how do firms ensure a sufficient supply of human capital when both demand and supply are both uncertain? Firms should seek to minimize mismatch costs by erring on the side of oversupply or undersupply, based on their relative costs.

The second question we must answer is, what are the different human-capital sourcing strategies available to firms, and when should each be used? This second question is closely related to the first, as the ability to minimize mismatch costs is a function of the array of 
available sourcing strategies and the risks associated with them (Swaminathan, Smith, and Sadeh, 1998). Clark (1989), for example, demonstrated the importance of considering the tradeoffs involved in choosing among internal versus external sourcing options. Key among these tradeoffs is the extent to which the available sourcing strategies ensure the reliability and responsiveness of the supply chain (Hendricks and Singhal, 2005).

\subsubsection{Reliability and responsiveness}

Reliability and responsiveness are key aspects of any supply chain's effectiveness (Beamon, 1999; Chen and Paulraj, 2004; Hendricks and Singhal, 2005). Reliability is the capacity to meet production requirements, including quantity, quality, timeliness, and availability. Not surprisingly, ensuring reliability is often quite expensive (Kim, 2011) and the costs of ensuring reliability are spread throughout the supply chain. Reliable suppliers can charge more because of the value they provide, incremental investments in product development can help to lower product failure rates (O'Conner, 2002), and investments in logistics can help to ensure timely delivery (Bodin, 1990). In the context of talent management, reliability translates into having the skills and capabilities on hand necessary to get jobs done. Ensuring such reliability often requires significant investments, such as maintaining a deep bench of talent and continuous investments in training and development.

Responsiveness is the capacity to adapt output or performance standards to changes in demand. Ensuring responsiveness can be equally costly. It is easier to sustain lower costs if volume and standards remain constant, but responsiveness requires flexibility, which in the modern economy translates to shorter lead times, essentially the ability to produce new products and newer versions of existing products, and the ability to increase or decrease production levels all at a moment's notice (Fisher, 1997). The necessary investments in technology and equipment needed to ensure such flexibility can quickly add up, especially when combined with the costs of using the market to address shortages in raw materials. In the context of talent management, responsiveness translates to the ability to quickly adjust humancapital levels to changing levels in demand as well as the ability to access and deploy new capabilities as needed. The costs of ensuring such responsiveness often include substantial investments in HR information systems (Dulebohn and Johnson, 2012) in addition to paying market premiums for instant access to qualified workers (Bidwell, 2011).

\subsubsection{Risk and uncertainty}

Problems of reliability and responsiveness are often related to labor (Cappelli, 2011a). Labor unrest, talent shortages, and retention challenges, such as the loss of a key employee, are threats to reliability that companies across the globe face to differing degrees. Contract terms, location, and transportation costs all have the ability to constrain firms' responsiveness. These problems are not necessarily routine, but they can be anticipated and, as a result, managed (Cappelli, 2011a: p. 312).

Knight (1921) was the first to distinguish risk from uncertainty. Risk relates to events that may be rare but that can be anticipated with some accuracy. Uncertainty relates to events that are largely unknown and extremely difficult to estimate. We can only manage problems when we have some ability to anticipate and predict the chance of the problems occurring. As a result, risk can be managed.

To this point, we have emphasized the role of uncertainty in generating mismatch costs. Problems of reliability and responsiveness, however, are much more like risk than uncertainty in that we can anticipate how they may unfold and, because they occur often enough, we have some reasonable sense of the likelihood that they will happen. We think about managing those problems under the general heading of risk management. The problem we face in making sourcing decisions is to choose the arrangement that does the best job of minimizing both mismatch costs and the risks of reliability and responsiveness (Cappelli, 2011a).

\subsubsection{Mitigation and contingency strategies}

Reliability and responsiveness problems arise from supply-chain disruptions (Hendricks and Singhal, 2005; Tomlin, 2006; Yu, Zeng, and Zhao, 2009), which include any event hindering the production and delivery of goods produced through the supply chain. Disruptive events range from small to large. In the manufacturing context, a small disruption may be the breakdown of a machine requiring repair, 
resulting in a temporary slowdown of the production process. Largescale disruptive events may include the shutdown of a major supplier or a natural disaster such as an earthquake shutting down production entirely (see Tomlin, 2006; Yu, Zeng, and Zhao, 2009 for more examples). Sourcing disruptions have been shown to have significant and long-lasting consequences on organizational performance. Analyzing disruptions in the supply chains of 885 publicly traded firms, Hendricks and Singhal (2005) found that firms experiencing disruptions, regardless of their cause, had negatively affected operating income, return on sales, and return on assets. Further, the average firm was unable to recover quickly, with the negative effects persisting over a two-year follow-up period.

In considering disruptions in the human-resource supply chain, it is helpful to think about the stock and flow of human capital within an organization (Größler and Zock, 2010). An organization's stock of human capital refers to the employees occupying each job at a given point in time, whereas the flow refers to the movement of individuals into, through and out of the organization. In a perfectly efficient supply chain, the flow of materials through the supply chain will ensure that the stock will always meet demand at any given point in time; in other words, the human-resource supply chain will always deliver the right amount of employees (with the right amount of skills) to each job. Setting aside the difficultly in predicting demand, several types of disruptions may occur. A small disruption may be a key employee going on maternity leave, while a large disruption might be a competitor hiring away an entire team of key employees (Groysberg, 2010). Both of these disruptions will result in an undersupply of human capital.

Disruptions can also result in oversupply of human capital. While manufacturing supply chains generally strive to eliminate losses (i.e., Brewer and Speh, 2000), organizations tend to expect some level of employee turnover, and often encourage turnover as a way to rid themselves of low performers and access new knowledge (March, 1991). Organizations often make hiring decisions at lower levels based on the expectation that some percentage of these workers will exit over a given time period. When such exits fail to occur, the firm is faced with an oversupply of talent. Similarly, when employees at higher levels fail to exit at the expected rate, as we see now with older employees staying in the workforce longer due to the recent market downturn (Conference Board, 2011), this creates bottlenecks that impede the advancement of qualified workers, increasing their likelihood of exit and the costs associated with those exits.

Supply-chain disruptions, whether those affecting manufacturing or human-resource supply chains, can be managed because they are events that we have some ability to anticipate, and thus we are able to predict the chance of the problems occurring. They represent risk. And supply-chain research has categorized possible solutions as falling into two distinct groups. Mitigation tactics involve the firm taking some action in advance of potential problems. Contingency tactics involve the firm taking action only when a problem actually occurs (Tomlin, 2006: 640).

These two sets of solutions differ in important ways. Mitigation strategies tend to handle problems more effectively, but involve more upfront costs; the firm incurs the costs regardless of whether a disruption actually occurs. Contingency strategies tend to be less effective, but no costs are incurred unless or until a disruption actually takes place.

A useful way to conceptualize these different approaches is to think of mitigation strategies as the equivalent of preventative medicine, and contingent strategies as the equivalent of emergency-room medicine (Cappelli, 2011b: p. 312). Carrying the medical analogy through, we see that sensible strategies for risk management rely on a mix of the two approaches depending on the problem. We might change our diet to help prevent a heart attack - a mitigation strategy - because it is much more effective than seeking treatment once a heart attack occurs. Rather than wear football pads at all times to prevent broken bones, we go to the emergency room when a break occurs - a contingency strategy.

\subsubsection{A typology of sourcing strategies}

Combining the two dimensions of supply-chain effectiveness (reliability and responsiveness) with the two approaches to dealing with supply-chain disruptions (mitigation and contingency) reveals four distinct sourcing strategies (Table 5.1). Which strategy to pursue depends on its value, which is equivalent to the losses it prevents, or the extent to which it minimizes the mismatch costs resulting from an oversupply or undersupply of human capital. That value is further enhanced when supported by a set of complementary organizational capabilities. 
Table 5.1 A typology of sourcing strategies

\begin{tabular}{lll} 
& Mitigation & Contingency \\
\hline Reliability & Inventory & Just-in-time back-up \\
& Complementary capabilities: & Complementary capabilities: \\
& Knowledge-sharing & External-market awareness, \\
& infrastructure, analytics & rapid talent acquisition \\
& (causal modelling, & (including assessment \\
& forecasting, simulations), & and onboarding); \\
& employee engagement and & benchmarking, supplier \\
& reward systems, training & collaboration \\
& and development & \\
Responsiveness & $\begin{array}{l}\text { Internal capacity } \\
\text { Complementary capabilities: }\end{array}$ & Complementary capabilities: \\
& Knowledge-sharing & Supplier collaboration, \\
& infrastructure, analytics, & contract negotiation, \\
& training and development, & performance monitoring \\
& learning orientation, & \\
& collaborative structure & \\
&
\end{tabular}

Building an inventory: a mitigation response to ensuring reliability Inventory responses are the most common mitigation strategies for ensuring reliability. The basic idea is simple. Carrying excess inventory provides a buffer against distuptions in supply. Carrying excess raw materials, for example, gives the organization time to find a new supplier if an existing supplier were to go out of business. More generally, the creation of inventories helps to avoid the effects of machine breakdowns, quality problems, and schedule disruptions in other links of the supply chain (Flynn and Flynn, 1999: 1024). In these ways, stockpiling inventory helps to minimize problems of reliability throughout the supply chain.

And while the general consensus is that inventories should be minimized in an effort to increase a supply chain's efficiency (Gunasekaran, Patel, and McGaughey, 2004), studies have consistently shown that firms often make a strategic choice to hold larger inventories in order to protect against potential disruptions, particularly against unreliable suppliers (Mabert and Venkataramanan, 1998).

In the talent-management context, the most common inventory strategy involves carrying a deep bench of internal talent. The firm bears these costs upfront, and they are often significant. The most straightforward costs include the salary and benefits paid to underused employees, but training and developments costs are often quite significant. A firm has to continually invest in its employees to ensure they are ready to maintain an expected level of performance when an opportunity opens.

A second, though less used, inventory strategy is maintaining a supply of internal temps who can step in to fill shortfalls when they arise. Substitute teachers are an example of such workers. They are employed by school districts to replace full-time teachers on an asneeded basis for reasons such as a personal illness, personal emergencies, attendance at workshops, and the like. Substitutes often receive health and retirement benefits in addition to participating in formal training programs funded by the school districts in order to ensure that they are able to provide a consistent level of instruction (Ostapczuk, 1994) - all cost the districts incur regardless of the how frequently the substitutes are actually needed.

Given the significant upfront costs necessary to maintain a humancapital inventory when the need for such an inventory may never materialize, an inventory strategy is likely to be most effective for those jobs and organizations where the costs of undersupply are greater than the costs of oversupply.

\section{Building internal capacity: a mitigation response to ensuring responsiveness}

Developing internal capacity is the most common mitigation strategy for ensuring responsiveness. Responsiveness problems can arise from unexpected changes in demand or disruptions in supply, with the primary issue being the ability to increase production levels in the face of increasing demand or maintain production levels in the presence of disruptions in supply. Both are typically met by investing in internal capacity in an effort to provide the flexibility necessary to deal with such problems should they occur. In a manufacturing context, for example, one such strategy might include building a distribution center larger than initially needed in the event demand will increase in the future. Another might include investing in an additional assembly line, which can be used when the original line is down for maintenance or can be used simultaneously with the original line should demand increase. 
In the talent-management context, investments in internal capacity include building recruiting and development capabilities that allow the firm to quickly hire and train workers to meet spikes in demand. They might also include investments in scheduling technologies allowing the firm to seamlessly schedule part-time workers during periods of peak demand, such as when retailers hire seasonal workers during the holidays. Continued investments in training and development, above that necessary for the current job, help ensure ready access to new skills and capabilities should they be needed. A simple example is offering tuition reimbursement for high-potential junior employees to develop managerial skills through an MBA program.

While helping to ensure responsiveness, all of these strategies involve significant upfront costs, investments that provide a positive return only if demand increases or there is a disruption in supply. Given the upfront costs involved, internal-capacity strategies are likely to be most effective for those jobs and organizations where the costs of undersupply are greater than the costs of oversupply.

It is worth noting that because both reliability and responsiveness are key aspects of any supply chain's effectiveness (e.g. Hendricks and Singhal, 2005), mitigation strategies to ensure reliability may overlap with strategies to ensure responsiveness. For example, while maintaining a ready supply of substitute teachers best represents an inventory strategy to ensure reliability, school districts also routinely invest in automated systems which allow them to keep track of available substitute teachers, send out alerts when a need arises, and coordinate the placement and scheduling of such teachers across multiple schools. These investments are akin to ensuring responsiveness by building the internal capacity necessary to meet fluctuations in the supply of and demand for substitute teachers.

Just-in-time back up: a contingency response to ensuring reliability Just-in-time (JIT) back-up responses are the most common contingency strategies for ensuring reliability. They represent the opposite of an inventory strategy; the firm carries no excess inventory, instead meet ing potential shortfalls by turning to external suppliers. In reviewing the vast literature on JIT supplier relationships, Frazier, Spekman, and O'Neal (1988: 53) emphasize that the distinguishing feature of such relationships is the emphasis on reliability, noting that "exactness is a critical consideration because the JIT exchange, in its extreme form, does not tolerate variances," with variance the antithesis to reliability. Finding a reliable supplier at the last minute, of course, can be quite costly. The tradeoff is that the firm only has to pay this market premium if and when a shortfall actually occurs.

In the talent-management context, there is a variety of JIT back-up options. Hiring externally is a common tactic for making up for skill shortfalls. However, the lack of information on external hires makes it difficult to ensure reliability, and overcoming this obstacle can be costly. For example, Bidwell (2011) has shown that employers tend to seek out external candidates possessing more observable signals of quality, such as education and years of experience, for which they pay a substantial salary premium compared to similarly qualified internal candidates. And at higher levels, companies are increasingly using search firms to fill key positions, also a costly proposition, as the typical fee runs upwards of $30 \%$ of the first-year base salary.

A more temporary option is using staffing agencies to provide workers who possess the necessary skills and capabilities needed to reliably perform the required tasks. If a worker underperforms, the firm can simply request they be replaced by the agency. This can also be an expensive way to ensure reliability, as the total costs for agency temporary employees, including agency mark-ups, often exceed those of comparable permanent employees (Barley and Kunda, 2004; Peck, Theodore, and Ward, 2005).

Whatever form they take, JIT back-up strategies can be costly. Yet these costs are only realized if and when a shortfall actually occurs. As a result they are likely to be most effective where the costs of oversupply are greater than the costs of undersupply.

Outsourcing: a contingency response to ensuring responsiveness Outsourcing is the most common contingency strategy for ensuring responsiveness. Rather than invest in the internal flexibility necessary to adapt to changes in demand and disruptions in supply, such changes are met by contracting with third parties to perform the work. Such tactics are similar to the JIT back-up strategy, but differ in that they focus more on outsourcing the unexpected work to vendors.

This distinction is clearer in the context of talent management, where the most common strategy is engaging a professional services firm to provide expertise on a limited basis. For example, a firm may be required to provide the government with an environmental study in 
order to obtain a permit for the construction of a new store. A smaller retail chain or one that expands infrequently may not have the capability to perform such an analysis. Rather than hire a geologist, civil engineer, and environmental engineer, they instead contract with a consulting firm with the expertise and capacity to perform a thorough analysis in a timely manner.

Like JIT back-up plan strategies, such strategies involve no upfront costs, but the costs of enacting such strategies when needed can quickly escalate based on level of demand, availability of third parties able to meet such demands, and amount of customization required. As a result, outsourcing strategies are likely to be most effective where the costs of oversupply are greater than the costs of undersupply.

Outsourcing is primarily about responsiveness, but can become a source of reliability if the relationship moves beyond a simple market exchange and toward a relational exchange, such as when the firm and vendor engage in repeated exchanges for similar services. Over time, such repeated exchanges have been shown to become more oriented to the prevention of defects, ensuring reliability (Frazier, Spekman, and O'Neal, 1988).

\section{Organizational capabilities}

The ability to capture the full benefit of these sourcing strategies will be greatest when supported by a complementary set of organizational capabilities. We highlight those capabilities most likely to unlock the value of each strategy, recognizing that this list is far from comprehensive and many capabilities may complement all strategies. For example, while we focus on how a knowledge-sharing infrastructure complements mitigation strategies, it may also support contingency strategies, as when organizations use vendor-management systems to centrally manage requests for temporary agency workers.

The successful execution of both the inventory and internal capacity mitigation strategies rely on a technological infrastructure able to facilitate knowledge sharing throughout the organization (Gold, Malhotra, and Segars, 2001). A centralized human resource information system (HRIS) containing detailed data on employee skills and performance and accessible to decision-makers throughout the organization is an important first step. However, for such systems to ensure reliable performance and responsiveness to changes, they must be embedded within an organization's overall decision-support system, used to aid in data-driven decision making both within and outside of the HR function (see e.g., Dulebohn and Johnson, 2012). Analytic capabilities are critical to enabling the development of metrics to assess the efficiency, value, and strategic impact of the human-capital supply chain and communicating those findings to business leaders in a language they understand (Boudreau and Ramstad, 2007; Dulebohn and Johnson, 2012). Those same analytic capabilities allow the organization to unlock the value of HRIS data by developing causal models, identifying leading indicators to forecast business and staffing requirements, and running sophisticated workforce optimization simulations in an effort to redeploy existing talent and develop the right mix of new skills internally (Größler and Zock, 2010; Harris, Craig, and Light, 2010).

Finding different ways to engage and reward underused employees is critical in executing an inventory approach, because the benefits of maintaining a deep bench of internal talent disappear if skilled employees leave before they are needed. These efforts can be supported by the same training and development capabilities necessary to execute an internal-capacity approach, which can also be supported by a culture embracing employee interaction and ongoing learning, both of which facilitate the development of new skills. Organizational structure can also help build internal capacity, as modular or project-based teams facilitate knowledge sharing and skill development across the humancapital supply chain (Gold, Malhotra, and Segars, 2001).

A JIT contingency strategy is supported by strong capabilities around the talent-acquisition process. In order to hire quickly and effectively, an organization must be aware of the location and availability of different skill sets on the external market at all times, have processes in place to quickly and accurately assess potential new hires, and have an onboarding process in place enabling them to begin contributing almost immediately. Benchmarking is also a critical capability, allowing the organization to evaluate its stock of human capital against the skills available in the market and to allocate the budget necessary to ensure that external offers will be competitive when they are extended. Developing collaborative relationships with staffing agencies can help maximize the value from such transactions by ensuring that the agency has access to a ready supply of workers meeting the specific needs of the organization as well as by providing the organization with valuable information on external labor market conditions (Dyer, 1997; Bidwell and Fernandez-Mateo, 2008). 
Collaboration is similarly important in executing an outsourcing strategy, especially in cases where an organization routinely engages the same vendor for similar work. The capability to structure and negotiate contract terms and monitor the work of external partners is also critical. Negotiating and including performance standards in sourcing contracts and developing metrics to monitor performance against those standards allows an organization to identify its best and worst performing suppliers, enabling it to shift sourcing requests away from poor performing suppliers while developing long-term relationships with its best suppliers (Gunasekaran et al., 2001, 2004; Harris, Craig, and Light, 2010).

\subsection{Theory and empirics}

The preceding pages provide an outline of the conceptual foundations of a supply-chain approach to talent management. While practitioneroriented literature has been quick to embrace these concepts (e.g., Bourdreau and Ramstad, 2007; Giehll and Moss, 2009; Wright et al., 2011; Hoffman, Lesser, and Ringo, 2012), empirical research in strategic human resources and related fields has been much more cautious in embracing such an approach. We suspect this is in large part due to two factors. First, no one has yet to clearly articulate its theoretic appeal. Second, the empirical challenges appear to be somewhat daunting. We attempt to address these issues below.

\subsubsection{Theoretic appeal}

Perhaps the most appealing aspect of a supply-chain approach is that it identifies a primary mechanism through which human-resource management affects firm performance. As convincingly argued by others, the key challenge facing researchers in the field of strategic human-resources management is demonstrating a causal link between human-resource management and firm performance (Lengnick-Hall et al., 2009; Huselid and Becker, 2011). While studies have shown that human-resource systems can have a significant positive effect on firm performance (e.g. Combs et al., 2006), the mechanisms by which human resources drive firm performance are less clear. As Ketchen and Hult (2007: 574) note, strategic supply-chain management involves managing the supply chain in a way that delivers products to customers and "enhance[s] key outcomes that drive firm performance." The supply-chain approach outlined above suggests that human resources can affect firm performance through minimizing mismatch costs.

Empirical work in the supply-chain literature has begun to demonstrate the negative economic consequences of high mismatch costs on firm performance (e.g. Hendricks and Singhal, 2005). Another way to interpret these findings is that lowering mismatch costs improves performance. Mismatch costs are a proximate measure of performance, what Becker and Huselid (2006: 907) refer to as an intermediate outcome with "a theoretically clear line of sight to the ultimate strategic (financial) outcomes." Such intermediate outcomes enable us to extend theory by probing the proverbial "black box" between humanresource systems and firm performance. Moreover, mismatch costs are a particular appealing intermediate outcome because they represent a financial measure and thus have a clear strategic significance.

A focus on mismatch costs also has the potential to advance our understanding of differential human-resource architectures within firms (Becker and Huselid, 2006). The key idea behind such an approach is that some employees (Lepak and Snell, 1999) and jobs (Kaplan and Norton, 2004; Huselid, Beatty, and Becker, 2005) create more value than others and thus should be managed differently. As noted above, the relative costs of oversupply and undersupply are likely to vary across jobs, suggesting the optimal strategies used to minimize these costs are contingent, at least to some extent, on the nature of the mismatch costs. Scholars have also struggled in figuring out how to identify strategic jobs. To the degree that higher mismatch costs indicate the strategic value of a job, estimating mismatch costs may provide a useful means for identifying strategic jobs (Huselid and Becker, 2011).

At its core, the supply-chain research we draw on is about decision making under conditions of uncertainty. It may be even more accurate to say that it is about managing risk through decision making. We think it is fair to say that human-resource scholars are well aware of the role of uncertainty in human-resource decisions. For example, the vast literature on personnel selection boils down to finding more effective ways to reduce uncertainty in the hiring process (see Sackett and Lievens, 2008 for an excellent review of the more recent literature). Yet uncertainty is rarely dealt with explicitly, in large part because we 
talk about uncertainty instead of risk (Knight, 1921). The concept of risk is more appealing (and we think more accurate) because it suggests something that can be managed. And we are able to forecast and predict most outcomes and their associated error rates. Indeed, the most influential recent work in the supply-chain field has been conducted by scholars who embrace the concept of risk and explicitly consider it in both their theories and models (see Chopra and Sodhi, 2004 for a straightforward discussion of risk in supply chains). We will concede that those models get complicated very quickly (something we address below), but they also provide a guide for more fully integrating risk into our theories and models.

An addition benefit, admittedly somewhat more empirical than theoretical in nature, is that adopting a supply-chain approach opens the possibility of using supply-chain management performance measures (Boudreau and Ramstad, 2001; Größler and Zock, 2010). Humanresource scholars have long called for better human-resource measures, measures that can be communicated throughout the organization to inform strategy making (Boudreau and Ramstad, 2003, 2006). The most widely used supply-chain outcome measures are particularly appealing because they tend to reflect intermediate outcomes with clear causal lines to organizational performance (Brewer and Speh, 2000; Gunasekaran, Patel, and Tirtiroglu, 2001). Gunasekaran and colleagues (2004) lump these performance measures into four categories, those related to planning, sourcing, assembling, and delivery.

We offer a few suggestions on how some of these commonly used measures might be translated to a human-resources context. One planning measure shown to be a source of competitive advantage is order lead time (Christopher, 1992), which refers to time that elapses between receipt of an order and delivery (Gunasekaran, Patel, and Tirtiroglu, 2001). Reductions in the time it takes to fill a vacancy or fill a newly created position are roughly equivalent to reductions in lead time. Supplier pricing against market is a commonly used sourcing metric that suggests the need to compare the prices paid for external hires and to third-party vendors against market benchmarks. Capacity utilization (Slack et al., 1995), an assembly measure, might be adapted to measure the utilization of recruiting and training capabilities. Number of faultless notes invoiced is used to determine whether perfect delivery has taken place or not, and to identify areas of discrepancy so improvements can be made (Gunasekaran, Patel, and
McGaughey, 2004: 337). Quality-of-hire metrics would be appear to be a similarly useful measure, as would performance variation among incumbents in a given job, with higher variation suggesting some employees lack critical skills (Huselid, Beatty, and Becker, 2005).

\subsubsection{Empirical challenges}

In the abstract, calculating mismatch costs is a straightforward exercise. The first step involves calculating the cost per excess worker (oversupply cost) and cost per worker shortage (undersupply cost). The second step involves calculating the number of excess workers (quantity of oversupply) or the actual shortage (quantity of undersupply). The mismatch cost equals the cost multiplied by the quantity. Given differences in jobs, the best estimates are likely to be calculated at the job level, which can then be aggregated at multiple levels (e.g., team, department, organization).

Of the two, oversupply costs initially appear to be the easiest to calculate. Given compensation and benefit data on job incumbents, a conservative estimate of the cost per excess worker in a given job can be calculated as the average annual cost per worker, the annual cost of the lowest paid worker (likely to be a lower bound), or the annual cost of the highest paid worker (likely to be an upper bound). These are only conservative estimates, however, because they do not include training and development costs invested in the excess worker, nor does it include estimates of turnover costs associated with losing a worker who may leave because of the lack of advancement opportunities associated with an oversupply of internal candidates. Estimating undersupply costs is likely to be even more difficult, as it involves projecting missed opportunities due to a lack of workers. In manufacturing roles, such a calculation may be relatively straightforward in terms of revenues lost per missing worker, but such a calculation would not account for additional costs such as damage to the firm's reputation, the loss of future opportunities stemming from the inability to meet demand in a given period, or even the search costs associated with quickly filling a vacant job. In more knowledge-intensive jobs and industries, estimating the costs of opportunities the firm was unable to pursue, for example, is even more problematic.

We do, however, sense that there are ways to overcome these issues. Our optimism comes, not surprisingly, from the supply-chain literature, 
where early researchers interested in these issues faced similar challenges. Our (admittedly incomplete) review of the supply literature suggests that partnering with organizations as a form of participatory action research (Whyte, 1990) is key.

One of the seminal articles in the field involved a long-term collaboration between the two researchers and an organization struggling with supply-chain issues (Fisher and Raman, 1996). Using both historic and real-time data provided by the organization, the researchers developed a decision model in which they were able to use parameters derived from the firm's own data. Based on a model using the same data available to the firm, they then executed their model in parallel with the firm's actual decision-making process in 1992-1993 and found that their model enabled the organization to cut the cost of both overproduction and underproduction in half, resulting in a significant increase in profits (Fisher, 1997). Moreover, a review of the recent supply-chain literature by Hendricks and Singhal (2005) reveals that empirical work quantifying the impact of supply-chain management practices on operating performance took off only after scholars became proficient in developing mathematical models of supply-chain issues, many of which resulted from close collaboration with the firms they were studying.

Adopting a similar approach, Größler and Zock (2010), partnered with a German service provider interested in overhauling their humanresource planning process. Using a combination of interviews and historical employment data from the firm, they were able to conduct a scenario analysis using a simulation model to estimate staff availability in various jobs under different sets of assumptions. An enterprising researcher willing to partner with an organization in a similar fashion would likely have the access to decision makers and historical data needed estimate job-level mismatch costs. The availability of simulation software packages would allow for estimating such costs under a variety of assumptions, which could then be tested using data from subsequent periods. Given the complexity of many supply-chain models, we see promise in future interdisciplinary collaborations, with human-resource researchers interested in applying a supply-chain logic to talent-management issues partnering with supply-chain researchers interested in exploring the wider applicability of their models.

A slightly different strategy would be to partner with human-capital consulting firms, many of which have already developed proprietary tools for estimating similar measures using data from their clients' HRIS. While their measures are likely subject to a number of shortcomings, they may offer a good starting point given that they are actually used by firms to make critical human-capital decisions. And while mismatch costs may be somewhat specific to firms and jobs, accumulating enough data on enough jobs in enough firms (a potential benefit of working with a consulting firm) should allow us to get a sense of the average mismatch costs (or the variables needed to estimate them) and apply them more widely. Doing so will allow us to subject our conceptual framework to empirical testing, such as exploring whether, as predicted, firms use different sourcing strategies based on the relative costs of undersupply and oversupply, and whether job and sourcing strategy fit leads to lower mismatch costs and improved organizational performance.

\subsection{Conclusions}

We are encouraged by the growing interest in integrating research on human-resource management and supply chains (Fisher et al., 2010). The majority of recent work has explored how the strategic management of human resources can support or improve the functioning of organizational supply chains. Studies in this tradition tend to focus either on the functioning of internal supply chains (e.g., Snell et al., 2000; Gowen and Tallon, 2003; Koulikoff-Souviron and Harrison, 2010) or the links between firms in the supply chain (Scarbrough, 2000; Jin, Hopkins, and Wittmer, 2010). A second stream of research explores how the logic of supply-chain management can improve talent management within organizations (e.g., Cappelli, 2008, 2009a; Größler and Zock, 2010). We believe this second approach, while less developed, provides fertile ground for future talent-management research. In an effort to provide a foundation for future research in this direction, we have used this chapter to outline the conceptual building blocks of a supply-chain perspective, its theoretical appeal, and to address how to overcome potential empirical challenges.

As a brief summary, minimizing the mismatch costs associated with the oversupply or undersupply of human capital is the central concern of a supply-chain approach to talent management. Because the costs of oversupply and undersupply are rarely equal, firms are able to choose among a variety of sourcing strategies in order to minimize their 
mismatch costs. Mitigation strategies are most effective when the costs of undersupply are greater than the costs of oversupply, as they often involve significant upfront costs. Inventory responses ensure reliability, while internal capacity responses ensure responsiveness. Contingency strategies are most effective when the costs of oversupply are greater than the costs of undersupply, as they lack upfront costs but can quickly get costly if they need to be used. Just-in-time back-up responses ensure reliability, while outsourcing responses ensure responsiveness.

We hope that our readers see promise in a supply-chain approach to talent management, recognize its theoretical appeal, and are emboldened to tackle the empirical challenges we have identified and those we have undoubtedly overlooked.

\section{References}

Barley, S. R. and Kunda, G. (2004). Gurus, Hired Guns, and Warm Bodies: Itinerant Experts in a Knowledge Economy. Princeton University Press.

Beamon, B, M. (1999). Measuring supply chain performance. International Journal of Operations and Production Management, 19 (3), 275-92.

Becker, B. E. and Huselid, M. A. (2006). Strategic human resources management: where do we go from here? Journal of Management, $32(6), 898-925$.

Bidwell, M. J. (2011). Paying more to get less: specific skills, incomplete information and the effects of external hiring. Administrative Science Quarterly, 56 (3), 369-407.

Bidwell, M. J. and Fernandez-Mateo, I. (2008). Three's a crowd? Under standing triadic employment relationships. In P. Cappelli (ed.), Employment Relationships: New Models of White-collar Work. Cambridge: Cambridge University Press.

Bodin, L. D. (1990). Twenty years of routing and scheduling. Operations Research, 38 (4), 571-9.

Boudreau, J. W. and Ramstad, P. M. (2001). Beyond cost-per-hire and time to fill: Supply-chain measurement for staffing (CAHRS Working Paper \#01-16). Ithaca, NY: Cornell University, School of Industrial and Labor Relations, Center for Advanced Human Resource Studies. http://digitalcommons.ilr.cornell.edu/cahrswp/79.

(2003). Strategic HRM measurement in the 21st century: from justifying HR to strategic talent leadership. In M. Goldsmith, R. P. Gandossy, and M. S. Efron (eds.), HRM in the 21st Century. New York, NY: John Wiley and Sons, pp. 79-90.
(2006). Talentship and HR measurement and analysis: from ROI to strategic organizational change. Human Resource Planning, 29 (1), 25-33.

(2007). Beyond HR: The New Science of Human Capital. Cambridge, MA: Harvard Business School Publishing Corporation.

Bretz, R. D., Boudreau, J. W., and Judge, T. A. (1994). Job search behavior of employed managers. Personnel Psychology, 47 (2), 275-301.

Brewer, P. C. and Speh, T. W. (2000). Using the balanced scorecard to measure supply chain performance. Journal of Business Logistics, 21 (1), 75-94.

Business Week (1949). Multiple management: top executive seedbed. Business Week, June, 82-3.

Cappelli, P. (1995). Rethinking employment. British Journal of Industrial Relations, 33 (4), 563-602.

(1999). The New Deal at Work: Managing the Market-driven Workforce. Boston, MA: Harvard Business School Press.

(2008). Talent on Demand: Managing Talent in an Age of Uncertainty. Cambridge, MA: Harvard Business School Press.

(2009a). A supply chain approach to workforce planning. Organizational Dynamics, $38(1), 8-15$.

(2009b). What's old is new again: managerial "talent" in an historical context. Research in Personnel and Human Resources Management, 28, 179-218.

(2010). The rise and decline of managerial development. Industrial and Corporate Change, 19 (2), 509-48.

(2011a). HR sourcing decisions and risk management. Organizational Dynamics, 40 (4), 310-16.

(2011b). Managing talent in a changing landscape. In K. Oakes and P. Galagan (eds.), The Executive Guide to Integrated Talent Management. American Society for Training and Development, pp. 13-22.

Carden, C. J. (1956). Executive training. Journal of Retailing, 22, 1-4.

Chandler, A. D. J. (1977). The Visible Hand: the Managerial Revolution in American Business. Cambridge, MA: Belknap Press.

Chen, I. J. and Paulraj, A. (2004). Towards a theory of supply chain management: the constructs and measurements. Journal of Operations Management, 22 (2), 119-50.

Chopra, S. and Sodhi, N. S. (2004). Managing risk to avoid supply-chain breakdown. MIT Sloan Management Review, 46 (1), 53-62.

Christopher, M. (1992). Logistics and Supply Chain Management. London: Pitman Publishing.

Clark, K. B. (1989). Project scope and project performance: the effect of parts strategy and supplier involvement on product development. Management Science, 35 (10), 1247-63. 
Clawson, D. (1980). Bureaucracy and the Labor Process: the Transformation of U.S. Industry 1860-1920. New York: Monthly Review Press.

Cohen, M. A. and Lee, H. L. (1988). Strategic analysis of integrated production-distribution systems: models and methods. Operations Research, $36(2), 216-28$.

Collings, D. G. and Mellahi, K. (2009). Strategic talent management: a review and research agenda. Human Resource Management Review, 19 (4), 304-13.

Combs, J., Liu, Y., Hall, A., and Ketchen, D. (2006). How much do highperformance work practices matter? A meta-analysis of their effects on organizational performance. Personnel Psychology, 59 (3), 501-28.

Conference Board (2011). More U.S. workers are delaying retirement. No. 350 May 2011. The Conference Board Inc.

Davis, G. F. (2009). The rise and fall of finance and the end of the society of organizations. Academy of Management Perspectives, 23 (3), 27-44.

DeVanna, M. A., Forbrum, C., and Tichy, N. (1981). Human resource management: a strategic perspective. Organization Dynamics, 23, $34-47$.

Dokko, G., Wilk, S. L., and Rothbard, N. P. (2009). Unpacking prior experience: how career history affects job performance. Organization Science, 20 (1), 51-68.

Dulebohn, J. H. and Johnson, R. D. (2012). Human resource metrics and decision support: a classification framework. Human Resource Management Review, 23 (1), 71-83.

Dyer, J. H. (1997). Effective interfirm collaboration: how firms minimize transaction costs and maximize transaction value. Strategic Management Journal, 18 (7), 535-56.

Fiorito, J. and Dauffenbach, R. C. (1982). Market and nonmarket influences on curriculum choice by college students. Industrial and Labor Relations Review, 36 (1), 88-101.

Fisher, M. L. (1997). What is the right supply chain for your product? Harvard Business Review, 75, 105-16.

Fisher, M. and Rayman, A. (1996). Reducing the cost of demand uncertainty through accurate response to early sales. Operations Research, 44 (1), $87-99$.

Fisher, S. L., Graham, M. E., Vachon, S., and Vereecke, A. (2010). Don't miss the boat: research on HRM and supply chains. Human Resource Management, 49 (5), 813-28.

Flynn, B. B. and Flynn, E. J. (1999). Information-processing alternatives for coping with manufacturing environment complexity. Decision Sciences, $30(4), 1021-52$.
Frazier, G. L., Spekman, R. E., and O’Neal, C. R. (1988). Just-in-time exchange relationships in industrial markets. Journal of Marketing, $52(4), 52-67$.

Ghemawat, P. (1986). Sustainable advantage. Harvard Business Review, $64(5), 53-8$.

Giehll, T. and Moss, S. (2009). Human Capital Supply Chains. Minneapolis, MN: Mill City Press.

Gold, A. H., Malhotra, A., and Segars, A. H. (2001). Knowledge management: an organizational capabilities perspective. Journal of Management Information Systems, 18 (1), 185-214.

Gowen, C. R. and Tallon, W. J. (2003). Enhancing supply chain practices through human resource management. Journal of Management Development, $22(1 / 2), 32-44$.

Groysberg, B. (2010). Chasing Stars: the Myth of Talent and the Portability of Performance. Princeton, NJ: Princeton University Press.

Groysberg, B., Lee, L. E., and Nanda, A. (2008). Can they take it with them? The portability of star knowledge workers' performance. Management Science, 54 (7), 1213-30.

Größler, A. and Zock, A. (2010). Supporting long-term workforce planning with a dynamic aging chain model: a case study from the service industry. Human Resource Management, 49 (5), 829-48.

Gunasekaran, A., Patel, C, and Tirtiroglu, E. (2001). Performance measures and metrics in a supply chain environment. International Journal of Operations and Production Management, 21 (1/2), 71-87.

Gunasekaran, A., Patel, C., and McGaughey, R. E. (2004). A framework for supply chain performance measurement. International Journal of Production Economics, 87 (3), 333-47.

Harris, J. G., Craig, E., and Light, D. A. (2010). The New Generation of Human Capital Analytics. Accenture Institute for High Performance.

Hendricks, K. B. and Singhal, V. R. (2005). Association between supply chain glitches and operating performance. Management Science, 51 (5), $695-711$.

Hoffman, C., Lesser, E., and Ringo, T. (2012). Calculating Success: How the New Workplace Analytics will Revitalize your Organization. Cambridge, MA: Harvard Business School Publishing Corporation.

Huselid, M. A. and Becker, B. E. (2011). Bridging micro and macro domains: workforce differentiation and strategic human resource management. Journal of Management, 37 (2), 395-403.

Huselid, M. A., Beatty, R. W., and Becker, B. E. (2005). “A Players" or "A Positions"? The strategic logic of workforce management. Harvard Business Review, 83 (12), 110-17. 
Jacoby, S. M. (1997). Are career jobs headed for extinction? California Management Review, 42 (1), 123-45.

Jin, Y., Hopkins, M. M., and Wittmer, J. L. S. (2010). Linking human capital to competitive advantages: flexibility in a manufacturing firm's supply chain. Human Resource Management, 49 (5), 939-63.

Judge, T. A. and Watanabe, S. (1995). Is the past prologue? A test of Ghiselli's hobo syndrome. Journal of Management, 21 (2), 211-29.

Kaplan, R. S. and Norton, D. P. (2004). Measuring the strategic readiness of intangible assets. Harvard Business Review, 82 (2), 52-63.

Ketchen, D. J. and Hult, T. M. (2007). Bridging organization theory and supply chain management: the case of best value supply chains. Journal of Operations Management, 25 (2), 573-80.

Kim, S. (2011). Strategic reliability investments in multi-indenture supply chains. Working paper. Yale School of Management

Knight, F. (1921). Risk, Uncertainty and Profit. Boston, MA: Hart, Schaffner and Marx.

Koulikoff-Souviron, M. and Harrison, A. (2010). Evolving HR practices in a strategic intra-firm supply chain. Human Resource Management, 49 (5), 913-38.

Kulda, R. J. (1980). The effects of strategic planning on common stock returns. Academy of Management Journal, 23 (1), 5-20.

Lee, H. L. (2002). Aligning supply chain strategies with product uncertainties. California Management Review, 44 (3), 105-19.

Lee, H. L., Padmanabhan, V., and Whang, S. (1997). Information distortion in a supply chain: the bullwhip effect. Management Science, 43 (4), 546-58.

Lengnick-Hall, M. L., Lengnick-Hall, C. A., Andrade, L. S., and Drake, B. (2009). Strategic human resource management: the evolution of the field. Human Resource Management Review, 19 (2), 64-85.

Lepak, D. P. and Snell, S. A. (1999). The human resource architecture: toward a theory of human capital allocation and development. Academy of Management Review, 24 (1), 31-48.

Mabert, V. A. and Venkataramanan, M. A. (1998). Special research focus on supply chain linkages: challenges for design and management in the 21 st century. Decision Sciences, 29 (3), 537-52.

March, J. G. (1991). Exploration and exploitation in organizational learning. Organization Science, 2 (1), 71-87.

Melman, S. (1951). The rise of administrative overhead in the manufacturing industries of the United States, 1890-1947. Oxford Economic Papers, $3(1), 62-112$.

Newcomer, M. (1955). The Big Business Executive: the Factors that Made him, 1900-1950. New York, NY: Columbia University Press.
Nkomo, S. M. (1987). Human resource planning and organization performance: an exploratory analysis. Strategic Management Journal, 8, 387-92.

O'Conner, P.D.T. (2002). Practical reliability engineering (4th ed.). West Sussex, England: John Wiley and Sons.

Olivares, M., 'Terwiesch, C., and Cassorla, L. (2008). Structural estimation of the news vendor model: an application to reserving operating room time. Management Science, 54 (1), 41-55.

Ostapczuk, E. D. (1994). What Makes Effective Secondary Education Substitute Teachers? Literature Review. Washington, DC.

Peck, J., Theodore, N., and Ward, K. (2005). Constructing markets for temporary labour: employment liberalization and the internationalization of the staffing industry. Global Networks, 5 (1), 3-26.

Princeton University (1949). Selected References on the Selection and Development of Executives. Industrial Relations Section, Princeton University.

Sackett, P. R. and Lievens, F. (2008). Personnel selection. Annual Review of Psychology, 59, 419-50.

Scarbrough, H. (2000). The HR implications of supply chain relationships. Human Resource Management Journal, 10 (1), 5-17.

Slack, N., Chambers, S., Harland, C., Harrison, A., and Johnston, R. (1995). Operations Management. London: Pitman Publishing.

Snell, S. A., Lepak, D. P., Dean, J. W., and Youndt, M. A. (2000). Selection and training for integrated manufacturing: the moderating effects of job characteristics. Journal of Management Studies, 37 (3), 445-66.

Society for Human Resource Management. (2002, 2004, 2006, 2008, 2011). SHRM Workplace Forecast.

Stalk, G. J. (1988). Time: the next source of competitive advantage. Harvard Business Review, 66, 41-51.

Strack, R., Caye, J.-M., Lassen, S., et al. (2010). Creating People Advantage 2010: How Companies can Adapt their HR Practices for Volatile Times. Boston Consulting Group and World Federation of People Management Associations.

Swaminathan, J. M., Smith, S. F., and Sadeh, N. M. (1998). Modeling supply chain dynamics: a multiagent approach. Decision Sciences, 29 (3), $607-32$.

Tomlin, B. (2006). On the value of mitigation and contingency strategies for managing supply chain disruption risks. Management Science, 52 (5), $639-57$.

Useem, M. (1993). Management commitment and company policies on education and training. Human Resource Management, 32 (4), 411-34.

Walker, J. W. (1980). Human Resource Planning. New York: Mcgraw-Hill.

Whitmore, E. (1952). The executive manpower shortage - and what can be done about it? American Business, 22 (8-9), 9. 
Whyte, W. F. (ed.). (1990). Participatory Action Research. Thousand Oaks, CA: Sage Publications.

Whyte, W. H. (1956). The Organizational Man. New York: Simon and Schuster.

Wood, D. R. and LaForge, R. L. (1979). The impact of comprehensive planning on financial performance. Academy of Management Journal, $22(3), 516-26$

Wright, P. M., Boudreau, J., Pace, D., Sartain, L., McKinnon, P., and Antoine, $\mathbb{R}$. (eds.) (2011). The Chief HR Officer: Defining the New Role of Human Resource Leaders. San Fransisco, CA: Jossey-Bass.

Yu, H., Zeng, A. Z., and Zhao, L. (2009). Single or dual sourcing: decisionmaking in the presence of supply chain disruption risks. International Journal of Management Science, 37 (4), 788-800.

Zunz, O. (1990). Making America Corporate. Chicago: University Of Chicago Press.

\section{6 \\ Employer branding and career theory: new directions for research}

GRAEME MARTIN AND JEAN-LUC CERDIN

\subsection{Introduction}

In this chapter, our aim is to combine insights from employer branding and career management to explain some of the issues facing the talent- and reputation-management agendas in organizations. More specifically, our objectives are:

1. to propose a revised model of employer branding and its links to talent management and organizational reputations, which are key elements in effective career management

2. to analyze links between employer branding and career management

3. to reflect on some of the problems raised by the interdisciplinary nature of employer branding in practice and the consequent implications for careers.

Previous research into employer branding and organizational reputations by one of the authors (e.g., Martin and Beaumont, 2003; Martin and Hetrick, 2009; Martin, Gollan, and Grigg, 2011) has led us to accept a working definition of an employer brand as:

a generalised recognition for being known among key stakeholders for providing a high quality employment experience, and a distinctive organizational identity which employees value, engage with and feel confident and happy to promote to others. (Martin, Gollan, and Grigg, 2011)

We argued that employer branding referred to the process by which branding, marketing, communications, and HR concepts and techniques were applied externally and internally to attract, engage, and retain potential and existing employees. Until the onset of the global financial crisis (GFC) experienced by many advanced economies, most practitioner-oriented work in the field has focused on talent attraction because of longstanding labor market conditions in developed and developing countries. Thus employer branding became associated with the external application of marketing and communications tools 